\title{
Epistemic and Ethical Considerations in the Direct-to-Consumer Health and Ancestry Genetic Testing Process
}

\author{
Katherine Huerne ${ }^{1}$ \\ ${ }^{1}$ McGill University \\ Correspondence \\ Katherine Huerne \\ Email: katherine.amber.li@mail.mcgill.ca \\ Publication Date \\ October 1, 2021
}

MJM 2022 (20) 11

https://doi.org/10.26443/mjm.v20i1.853

\section{McGill Journal of Medicine}

www.mjmmed.com

\section{(1) (2) (2)}

This work is licensed under a Creative Commons BY-NC-SA 4.0 International License.

\section{ABSTRACT}

Background: Direct-to-consumer genetic testing (DTC-GT) is a popular and fast-growing field within the healthcare industry. Consumers often pursue DTC-GT without a clear understanding of its epistemic and medical limitations. This report will present the current state of DTC-GT technology, and highlight the ethical, legal and social issues of DTC-GT.

Methods: Quantitative sources such as systematic reviews were used to evaluate the field of DTC-GT. Experimental data was taken from randomized control trials and case studies of 23andMe. Qualitative sources such as newspaper articles and surveys were also used. Relevant policies and regulatory information were analyzed in the context of 23andMe as a case study. Broader ethical issues are analyzed from the social disability model and feminist ethics frameworks.

Results: Several aspects of direct-to-consumer genetic testing are outlined: (i) regulatory and legal distinctions of DTC-GT that separate its use from conventional genetic testing, (ii) epistemic issues of the genetic testing process within the direct-to-consumer context, and (iii) ethical considerations of DTC-GT regarding genetic health and genetic ancestry.

Conclusion: This report does not take a position for or against the use of DTC-GT; rather, it highlights the key ethical issues often missed in the DTC-GT process. There is no perfect method for understanding genetic health and race. DTC-GT offer consumers the ease and power of taking genetic data 'in their own hands', at the cost of exacerbating geneticization and race essentialism. Until further work is done to address the epistemic, regulatory and legal issues, ethical implications of DTC-GT usage will continue to exist.

\section{KEYWORDS}

Direct-to-consumer, Genetic testing, Ethics, Epistemology, Guideline 


\section{1 | INTRODUCTION}

This report aims to provide an ethical framework on direct-to-consumer genetic testing (DTC-GT) of health and ancestry genetics for stakeholders and individuals interested in the DTC-GT process. Findings suggest that epistemic issues in health and ancestry genetic data interpretation lead to ethical consequences of geneticization (1) and race essentialism (2), respectively. The ethical analysis will be centered on the case study of 23andMe, a US-based DTC-GT company. A brief overview of the DTC-GT process will be presented, alongside an epistemic analysis of its scientific validity. The discussion will be linked to the broader ethical consequences of geneticization and race essentialism, analyzed using a social disability and feminist ethics framework. This report does not take a position for or against the use of DTC-GT; rather, it presents a clear framework of ethical considerations for the consumer to interpret. Alternatives to DTC-GT will be proposed, such as clinical genetic counseling, epigenetic sequencing and metagenomic sequencing. Ultimately, DTC-GT will be contextualized within the greater scope of molecular screening technologies and the field of bioethics.

\section{2 | METHODS}

This paper draws on quantitative sources such as systematic reviews to report the field of DTC-GT. Clinical data was taken from randomized control trials and case studies of 23andMe which fulfilled ethics approval. (313) Qualitative sources such as newspaper articles and surveys were also used. (14-18) The sources were retrieved through a query search on Google Scholar and PubMed in November 2020. The keywords used in the search were: direct to consumer, genetic testing, 23andMe, ancestry, health, ELSI, ethical, legal, social, epistemic, issues, interpretation, consumer, legal, policy, terms of use. Relevant policies and regulatory information were analyzed in the context of 23andMe (19-24) as a case study intended to represent the process of DTC-GT for an average consumer. Claims about
23andMe were cited from the company website, policies, and terms of use. Broader ethical issues are analyzed from the social disability model and feminist ethics frameworks, defined as:

- Social disability framework (25): that the conception of 'disease' is not a product of genetic or clinical anomalies, but a product of barriers and lack of (medical/political/social) accommodations that render an individual 'disabled' within their specific social context.

- Feminist framework (26): that the individual is situated within a social web of intersectional relationships, and power hierarchies are maintained through existing social structures.

\section{3 | DISCUSSION}

\section{1 | 23andMe, and epistemic problems of direct-to-consumer genetic testing}

\subsection{1 | Regulatory and legal distinctions of DTC-GT}

DTC-GT refers to the branch of commercial services offering personalized sequencing and analysis of individual DNA. Testing services can reveal either ancestry (via genealogy or racial breakdown) or health (via genetic markers or health traits) information, or both, by sequencing genomic DNA. (19) This service can be offered by a private company (such as $23 \mathrm{andMe}$ ) after paying an upfront fee. It is important to understand the context DTC-GT operates under, as several aspects distinguish it from the clinical genetic counseling practices people may be used to. For example, legally speaking, the individual is not considered to be a patient but a consumer $(20,27)$. In other words, the process is generally seen as the purchase of a consumer good and not a regulated health service. This legal distinction forms the basis for how consumer data is analyzed and protected. DTC-GT might be advertised to be scientifically informative, but they may not be legally considered a diagnostic tool. (3) In other words, consumers should look to DTC-GT for 
recreational and not diagnostic purposes. Any company that markets their tests as a diagnostic tool without the legal jurisdiction over-promises their scope of regulatory and legal protection to consumers. ${ }^{*}(3)$

Clinically speaking, this service does not operate under the regulatory guideline of a professional medical order (4), and thus may lack third-party harmonization and regulation in terms of conduct. DTC-GT allows the consumer to bypass administrative barriers associated with the ordered healthcare system, culminating in a faster and more autonomous experience of genetic testing. (27) Typically, genetic testing under the clinical setting requires a physician's referral and genetic counsellors to interpret the information, which typically takes months to proceed. (3) For DTC-GT, standardized procedures allow the entire process to be completed in a 3-5 weeks from the time of purchase. (28) The tradeoff for speed, ease-of-access, and autonomy in DTC-GT is a compromise in regulatory policies that serve to protect individuals. For example, informed consent should be explicitly obtained and maintained during the entire clinical process, while consent in DTC-GT may be ambiguously presented or obtained only once at the time of purchase. (29) Consumers should be aware that these subtle differences in regulatory and legal practices impact the way their genetic data is stored, processed and interpreted. Thus, the decision to undergo DTC-GT entails more than just purchasing a service.

\subsection{2 | Epistemic issues of the DTC-GT process}

When a DTC-GT test is ordered, consumers are sent a testing kit to collect their DNA, such as a saliva sample in the case of 23andMe. (19) The sample is sent to a testing center where high-throughput (HTP) sequencing technologies are used to amplify, read and record specific parts of DNA sequences in parallel. (5) The sequences are then transferred to a computer database and 'analyzed' by comparing the individual sequence to a 'reference genome' composed of healthy individuals from a variety of racial backgrounds. (5) Thus, the 'interpretation' aspect of DTC-GT relies on pre-established standards as the reference point of comparison, removing the need for a genetic counsellor to interpret test results on an individual basis. In this sense, DTC-GT consolidates the sequencing and interpretation process of genetic screening into one mass-produced service. (19) The genomic differences of individual consumers are not analyzed from a personalized perspective but compared across a generic standard.

The interpretation of DTC-GT data poses epistemic issues regarding the scientific validity of what the tests claim to reveal. (14) Firstly, 23andMe markets a broad and in-depth analysis of DNA. (19) In reality, the entire human genome is not sequenced - due to the limitations of HTP sequencing technologies and the enormity of the human genome, such a feat is costly, timeconsuming and outside the feasibility of a commercialized company aiming at rapid genetic results. (30) Instead, only a selection of single nucleotide polymorphisms (SNPs) is sequenced within DNA.†(30) This process is what 23andMe calls 'qualitative genotyping' (21): selecting clinically relevant variants in various parts of genomic DNA, then associating a particular SNP to some disease or ancestry lineage. It is qualitative because the process relies on human cognition to determine which exact SNP to select for, and what effect it has on a given health/ancestry outcome. In other words, the interpretation of SNP variance depends on the subjective interpretation of the company's genetic counsellors and data analysts.

Moreover, the way that 23andMe advertises qualitative genotyping presumes that SNP variance is a direct agent of disease or ancestry. (31) Such a claim is under epistemic contention as basic research is constantly challenging the causal perception of genomics. Furthermore, it is not always the case that a particular SNP variant (genotype) produces a certain health/ancestry state (phenotype), or that a particular phenotype is due to genetic abnormalities (it could also be due to issues at the epigenetic, RNA, or protein level, for example). (31) It could also be the case that the true genomic 'cause' was missed entirely by the company's analytical process, due to a lack of SNP selective pressure or scientific knowledge. (31) Thus, any marketing claim which purports to 
advertise a comprehensive or objective view of genomic analysis is misleading, as only a fraction of the genome is examined, and the results are largely filtered by a selection bias of known SNPs only. (32)

In the case of health data, the individual's SNPs are compared to the SNPs of the reference genome in order to determine if the individual is a carrier for a particular disease. (22) If an anomaly is detected, it simply means the individual has a mutation or allelic variant that does not exist in the reference genome. (30) As correlation does not imply causation, it is important for the consumer to understand that 'disease status' of a DTC test result does not mean the consumer will necessarily develop the disease itself. This distinction is made clear in the fine print of a DTC company's legal regulations. Although 23andMe's 'Genetic Health Risk' and 'Carrier Status' tests advertise meeting the criteria for being scientifically and clinically valid, their legal policies also claim that:

\begin{abstract}
"The test is not intended to tell you anything about your current state of health, or to be used to make medical decisions, including whether or not you should take a medication, how much of a medication you should take, or determine any treatment. Our carrier status reports can be used to determine carrier status, but cannot determine if you have two copies of any genetic variant. These carrier reports are not intended to tell you anything about your risk for developing a disease in the future, the health of your fetus, or your newborn child's risk of developing a particular disease later in life." (19)
\end{abstract}

Therefore, the health tests should not be seen to claim any more than a qualitative interpretation of SNP variance. DTC-GT companies like 23andMe may use vague marketing of their diverse SNP variants to obscure this point(4). For example, 23andMe advertises their tests to be "clinically and scientifically valid" (19), and yet in fine print, they disclose that not all health re- ports are FDA approved, nor are the tests intended to reveal a person's state of health, determine carrier status, or assess the risk of developing a certain disease. (24) In reality, SNP variance should not be seen as more than a correlation to health/ancestry. DTC-GT companies could do more to clarify this epistemic distinction, instead of listing it as fine prints and footnotes in their policies.

For ancestry analysis, the similarity of the individual's SNP haplogroup is compared to the SNP haplogroups of 14,437 people with known ancestry in the 23andMe database. (23) Ancestry data is found by comparing individual sequences to other individuals in the database, while racial breakdowns are tracked in correlation with historical human migration of distinct ethnic groups. (23) The specific percentage of racial or ancestorial breakdown is thus determined based on what proportion of a consumer's DNA matches some individual or group reference genome. (23) There are three types of sequencing (autosomal, mitochondrial, and X/Ychromosomal) that 23andMe employs. (23) While each type sequences a different part of the genome, all methods face various degrees of contention regarding its scientific validity. Ancestral testing requires a higher degree of qualitative interpretation than genetic health data, as the reference genome is based on a qualitative determination of perceived 'race' to geographical locations. (33) As empirically hard as it is to prove that genetic anomalies cause some disease, it is harder to prove that genetic similarities are due to links in genealogy. (33)

Furthermore, it is unclear whether a person's genetic ancestral lineages are due to common geographical origins(33), an assumption that ethno-geographical analyses make. There is also the issue of accuracy and precision in ethnicity-based analyses. (33) Technological limitations in genealogical sequencing can establish the continental origins of an individual with relative precision, but fails to accurately distinguish between different ethnicities within a given continent. (23) This is partly because Western-American genetic research has disproportionately focused on people of European descent as the reference genome, such as the 
case of 23andMe, which disproportionally focuses on Ashkenkazi Jews of Eastern Europe. (23) As a result, testing sensitivity is highly sensitive to the genetics of Ashkenkazi Jews while being unable to distinguish between sub-populations of non-European continents. (23) Yet, 23andMe advertises a precise ethnic breakdown of race genealogy by any country, a feat overexaggerated except for (Jewish) European ethnicities. In fine print, 23andMe warns it cannot detect the ancestry of people with mixed ethnicities (admixture), or determine which marker came from which parent, thereby compromising the ability of the test to report accurate genealogical data. (23)

Lastly, the contention of scientific validity is further reflected in the turbulent history of 23andMe and its regulatory battle with the United States' Food and Drug Administration (FDA). 23andMe was founded in 2006, and initially operated without public health regulation as a commercial service in California. (15) Only in 2009 did New York and California mandate 23andMe to obtain a Clinical Laboratory Improvement Amendments (CLIA) license to continue business. (15) Since 2008, the US FDA required the regulation of 23andMe tests as medical devices, with federal approval to market its service. (15) In 2013, the FDA sent a warning letter to 23andMe, as the company had not "analytically or clinically validated the personal genome service for its intended uses."(15) In other words, 23andMe's test results showed high variance in reproducibility on ancestral lineages, and the SNPs were claiming too much unproven health risks. As a result, 23andMe suspended its healthrelated genetic tests and scaled back its range of SNPs while undergoing regulatory review. (15)

Upon their subsequent efforts to follow FDA regulations, their services began to resume and in 2014, they expanded their services to Canada, Australia, and the United Kingdom. (15) However, the FDA was clear to establish that test results could only be marketed for genetic screening, not genetic diagnosis. (34) In other words, the tests cannot predict with scientific certainty an individual's risk of developing a disease or their ancestral background. The extent of genetic testing could only report specific variants within a person's genome, but not what the variants necessarily mean. Such a history of regulatory contention is not unique to 23 andMe $(6,7)$. Many DTC-GT companies face regulatory restrictions that are not publicly disclosed to consumers during the advertisement process. The question of regulatory harmonization also becomes an issue when companies operate in a different country (i.e.: USA) than what they market to (i.e. Canada), impacting the scope and quality of tests that a company can offer. Therefore, it is important for consumers to check the scope of DTC-GT regulation for their country, as it can affects how genetic data is used and interpreted.

The legal, epistemic and regulatory issues in data interpretation compromise the scientific validity of DTCGT. These issues are not a problem in and of itself as long as consumers are aware of what the tests really measure. However, these issues become problematic due to ethical consequences that can arise as a result of undergoing DTC-GT. Consumers who do not understand the full extent of what these tests claim may mistakenly believe sweeping generalizations about their genetics or engage in detrimental behavior that they otherwise would not make without the test results. Without the guidance of a clinical genetic counsellor to interpret the data, the duty falls on the consumer to be wary of ethical complications. The next section provides a framework on common ethical issues arising from DTC-GT, so that consumers have the necessary tools to make their own decisions regarding health and ancestry genetics.

\section{2 | Ethical considerations in direct-to-consumer genetic testing}

This section will analyze broader contextual issues of DTC-GT from the ethical frameworks of social disability and feminist ethics. Although these frameworks are used to center the ethical discussion of DTC-GT, they are not exhaustive, and the same situation could be examined from other ethical frameworks (i.e. utilitarianism, liberalism, virtue ethics). 


\subsection{1 | Genetic health: geneticization, disability and harmful behaviors}

One of the biggest ethical concerns which coincided with the development of genetic testing in the early 1990's was the idea of geneticization (35): the tendency to define differences between individuals as largely or entirely based on genetics. This definition in the context of genetic testing implies that there is some predictable correlation of genetics (the DNA sequence) to an observable phenotype. DTC-GT companies like 23andMe rely on this paradigm to advertise their services. This is evidenced by 23andMe's marketing of their genetic tests to reveal some 'essential' characteristic about a person's genome through a genetic "health predisposition" or "carrier status" test. (36) However, geneticization can lead to genetic discrimination, which is the partial and unfavourable treatment of individuals within social, political, or legal planes due to differences in their genome. Genetic discrimination is problematic, especially in the context of disease management, because decisions regarding the wellbeing of humans are made on the basis of a qualitative interpretation that a person's genome correlates to some physical or psychological state. (35) In reality, scientists and experts alike recognize this reductionist belief rests on shaky epistemic grounds; as we have seen, a person's genome may not necessarily be a direct cause of disease.

The ethical implications of geneticization go beyond what a DTC test result states. Today, geneticization and genetic discrimination can be embodied through health insurance practices for example. In Canada, Bill S-201 was passed in 2017 to prohibit the use of genetic test results to determine insurance claims below $\$ 250,000$. $(16-18)$ Though this law aims to prevent genetic discrimination, insurance companies can still ask and encourage individuals to disclose their DTC-GT results. (16) This law was made in an effort to combat specific practices of genetic discrimination, but it does not stop insurance companies from promoting the idea of geneticization as an ideology. Geneticization is the underlying belief that allows genetic discrimination to manifest in different ways. Barring one form of genetic discrimination does not prevent other forms to take place or develop as a replacement. Laws stand to regulate existing practices, not ideologies. (37) Therefore, consumers should be aware of the larger ethical consequences and 'what it means' to disclose their genetic information. Allowing insurance companies to obtain DTC-GT blurs the distinction between geneticization as a theoretical concept and genetic discrimination as a tangible practice.

Another consequence of geneticization is the tendency for DTC-GT to promote risky behaviour in the name of preventative healthcare. $(8,38)$ Without the guidance of a genetic counsellor, consumers may engage in harmful actions that they would otherwise forego. Such is the case of buying black-market prescription drugs to pre-emptively 'cure' a disease, or undergoing surgery because test results revealed a variant of cancer. (8) In a study of 25 individuals who underwent 23andMe's testing service and tested positive for BRCA1/2 variants of breast cancer, 4 individuals underwent preventative surgery for the sake of risk reduction, before actually developing the cancer. (9) This contradicts the scientific evidence stating there is currently no effective genetic screening protocol that can reduce mortality from ovarian cancer for those who carry BRCA1/2 pathogenic variants. $(10,39)$ In other words, 23andMe testing encouraged individuals to undergo potentially unnecessary surgical procedures. As mentioned, having a genetic variant does not guarantee the result of developing a disease, but undergoing surgery guarantees subjecting the individual to all associated surgical risks. $(11,40)$ Most often, DTC-GT companies do not explicitly inform consumers of the risks of 'preventative healthcare', nor do they prevent consumers from engaging in harmful behaviours after the test. (41)

Lastly, social disability ethicists argue against the idea of geneticization, as they do not support the conceptualization of health on a genetic basis. (25) This is because there is an epistemic barrier between genetic conceptions and lived experiences of disease. (42) In other words, people do not 'know' what it's like to live with a genetic variant, but people know what it is like to feel 
debilitated in health. Social disability ethicists would argue the debilitating experience is better embodied by social descriptions (43); health is shaped by a variety of elements, with genetic variation being only one element to consider. DTC-GT can also become a burden to health if it increases anxiety or promotes risky behaviour. $(43,44)$ Instead, social disability ethicists believe whether an individual has a negative or positive outlook to their health largely depends on how society treats them and the access to accommodations that society provides. (25) Individuals should not need a genetic test to legitimize their embodiment of disease or make proactive decisions regarding their wellbeing. They can look to other aspects of healthcare (such as caregiver support, workplace accommodations, etc.) to address a variety of bodily standards and functions. (43) Social disability theory thus works to oppose the very ideology of geneticization, and argues that the idea of disease/disability is not due to a person's inherent (genetic) nature, but a product of societal barriers.

\subsection{2 | Genetic ancestry: racial constructions, essentialism, and racism}

The main ethical debate surrounding genetic ancestry tests is the distinction between race essentialism and socially constructed views of race.§ Race essentialism is the belief that race has a biologically distinct and quantifiable 'nature'. (2) In the context of DTC-GT, it means race can be defined by the specific composition of genetic haplogroups, leading to an individual being characterized as $40 \%$ Irish and $60 \%$ Native American, for example. However, it is important to understand that race essentialism developed as a consequence of the Human Genome Project and the genomic revolution in the 1990s (46), with ethical correlations to geneticization discussed earlier. Essentialism contrasts the idea that race is a social construction: a product of personal and social identities, contextually situated and dynamically evolving in time. (47) For example, an African or a Black American may have the same genetic composition of race, but their conceptualization of personal race would be different because of ethnic differences in cul- tural practices, beliefs and societal context.

The idea of race as a social construction has an ethical basis in feminist frameworks of relational autonomy, where our racial and ancestral identity is related to our conception of the 'self' as socially embedded agents in society. (47) The conception of the 'self' exists as a relational identity to intersecting social determinants, such as race and ethnicity, but also sex, gender, class, etc. (47) Thus, 'whiteness' is defined not only by a person's genetic race, but by the social privileges or disadvantages afforded to a particular identity of race within the greater set of cultural norms and practices in which they exist. (47) For feminist ethics, racial identity is not defined by a person's genetic links to outward appearance, but instead on social practices that shape how society treats individuals based on their outward appearance.

The ethical distinction between race essentialism and social construction rests on how we use these racial frameworks to justify social phenomena. Race essentialism becomes problematic when it leads to racism and discrimination on the basis of genetics. (4) This can be exemplified by using ancestral genetics to justify discriminatory health practices, such as the BiDil controversy which saw the FDA approve race-based drugs without a clear empirical link between race and biology. (48) It sensationalized race genetics for commercial and regulatory gain, for a Black community that already faces racial discrimination in other aspects of their lives. (48) This situation is analogous to what can happen in race-based approaches to health. A 23andMe study showed that people of Ashkenazi Jewish ancestry are genetically predisposed to BRCA1/2 mutations. (12) Should we consequently create a similar race-based solution to targeting breast cancer in Ashkenazi Jews, or promote further studies using this approach? Answering 'yes' presumes accepting the viewpoint of genetic essentialism, but could be challenged upon the observation that 23andMe's reference genome draws heavily on individuals with Ashkenazi Jewish ancestry. (23) It is expected that health risks will correlate with Ashkenazi Jewish ancestry when the reference genome is composed of these individuals. This issue of questionable science becomes an ethical issue when race-based prac- 
tices are used to differentially treat certain populations over others.

Furthermore, racial essentialism can lead to identity politics issues of gatekeeping on the basis of genetics. (49) Someone of mixed American ancestry could be denied Native-American status on the basis of not having enough genetic Native ancestry, despite adopting Native cultural norms and practices in their life. (49) This form of genetic essentialism stems from the epistemic issue that Western-American DTC-GTs lack reference data for non-European races. (23) These examples highlight not only the epistemic limitations of race essentialism, but also the ways social constructions of race could be a better tool to inform our understanding of race. Essentially, race according to genetic essentialism shifts the focus away from real issues of race (like racism), while legitimizing racial discrimination on the basis of genetics.

The last ethical dimension in ancestry genetics looks at the relationship between race essentialist beliefs and extent of genetic knowledge. A randomized control trial investigating the influence of genetic ancestry tests on racial essentialism showed that:

\section{"Essentialist beliefs significantly declined after testing among individuals with high genetic knowledge, but increased among those with the least genetic knowledge. ... These results indicate that individuals' interpretations of genetic ancestry testing results, and the links between genes and race, may depend on their understanding of genetics" (13)}

How we understand race depends on how well we understand epistemic limitations in the genetic testing process. The more informed the individual is on the biases of the process, the less likely they will adopt racial essentialist beliefs. (13) This phenomenon is not a major ethical concern in clinical contexts of genetic testing, as genetic counsellors are present to interpret genetic data from an external perspective. However, DTCGTs lack the epistemic diversity of genetic counselors.
(13) In consolidating genetic screening + data interpretation into one unified process, consumers are exposed to the one (and often essentialist) view of race interpretation promoted by DTC-GT companies. (46) In this sense, there is a greater ethical duty for consumers to avoid essentialist-based beliefs by not taking the company's interpretation of race/ancestry genetics at face value. For this reason, greater caution must be taken before adopting race-based views of genomic analysis.

\section{4 | CONCLUSION}

So far, this report has listed the main ethical issues of health and ancestry DTC-GT, arising from epistemic issues related to the interpretation of genetic data. I have highlighted how the DTC-GT process frames individuals as consumers, and the regulatory consequences that comes with this distinction. I have also explained some epistemic issues behind the scientific process of the genetic testing process, and how a misinterpretation of genetic data can lead to ethical issues of geneticization and race essentialism.

Broadly speaking, there are further ethical considerations of DTC-GT not covered by this paper, such as:

- Informed consent: DTC-GT companies may not present to consumers a clear understanding of the testing, interpretation, and usage of information process. (4)

- Data privacy: the scope of privacy policies may not protect consumer genetic data from its usage of data in non-commercial purposes, especially when privacy/Terms of Use policies can be changed anytime by the companies that set them. (4)

- Biobanking: the storage of genomic data for preand post-commercial usage can complicate ownership and usage rights of genetic information. (50)

- Further research: questions of what is owed (monetary compensation or otherwise) may not be addressed when a company uses consumer data for internal/external research. (33)

- Regulatory scope: lack of regulatory harmonization 
and third-party enforcement of DTC-GT companies means that all the ethical concerns above are subject to the (mis)management of the company itself. (4)

These issues extend beyond the scope of epistemic data interpretation, but nonetheless are important issues to take into account when choosing to undergo DTC-GT.

DTC-GT may seem like an attractive option because it is commonly marketed to individuals. Consumers should realize that DTC-GT is not the only way to be proactive about personal health. Alternatives to DTCGT include:

- Clinical sequencing with counselling: the conventional path of working with genetic counsellors can alleviate epistemic issues regarding data interpretation, but ethical issues of geneticization/essentialism can still persist in lieu of a good counsellor. (51)

- Epigenetic screening, RNA/protein assays: these profiles reveal different molecular states not covered in DTC-GT sequencing, and challenges epistemic misconceptions about the sole causal agency of genetics to disease. (52)

- Metagenomic sequencing: a profile of commensal microbial entities can highlight its interaction with host systems in its native environment, further dispelling epistemic misconceptions about the 'essentialist' effect of host DNA. (53)

All these processes reveal some other aspect of a person's molecular composition and when done in combination, can paint a diverse molecular profile that moves away from a causal genomic view of molecular processes. However, each method also poses ethical concerns regarding genetic reductionism, and not all processes have been adapted for large-scale clinical application. (53)

There is no ideal method for understanding genetic health and race. Direct-to-consumer genetic tests offer consumers the ease and power of taking genetic data 'in their own hands', at the cost of compromising scientific validity and potentially exacerbating epistemic- driven ethical issues of geneticization and race essentialism. (53) Though the ethical issues were formulated in the context of 23andMe, it is important to realize that other DTC-GT companies face similar ethical complications. (53) The consequences of geneticization will always be an issue when a company markets its business on the essentialist basis of genetics.

This report does not take a position for or against the use of DTC-GT; rather, it aims to highlight key ethical issues not explicitly addressed when consumers undergo the DTC-GT process. Until further work is done to address the epistemic, regulatory and legal issues, ethical implications will continue to exist. The issues thus presented provide consumers with the knowledge to make their own decisions regarding DTC-GT. The decision to pursue DTC genetic testing comes down to a matter of weighing personal values and tradeoffs: privacy, power of knowledge, speed of testing, scientific/epistemic validity, harms/risks, and broader ethical consequences are all factors to take into consideration. Perhaps, the best avenue for understanding health and ancestry is to forgo the genetic approach altogether; social disability and feminist ethics would advocate for a more comprehensive social understanding of health and ancestry as opposed to striving for genetic legitimacy.

\section{$5 \mid$ NOTES}

* It is advisable for consumers to gauge the exact legal scope of the specific DTC-GT company of interest, for their specific geographical location. Some small subset of DTC-GT may be considered diagnostic, depending on regulatory policies of their geographical location Any lack of legal information should be assumed recreational.

† SNPs are areas of the genome with the highest rate of variance (a single base pair mutation) at a specific locus, which is often correlated to some phenotype.

‡ Canadian insurance companies already use discrimination (by habit, occupation, age, weight, etc.) to determine eligibility and rates of coverage. The law prevents further discrimination on the basis of genetic test 
results.

$\S$ Definitions of race and ethnicity: "Race is usually associated with biology and linked with physical characteristics such as skin color or hair texture. Ethnicity is linked with cultural expression and identification."(45) In the context of DTC-GT, 'race' refers to the former biological context.

\section{REFERENCES}

1. ten Have HAMJ. Genetics and culture: The geneticization thesis. Med Health Care Philos. 2001;4(3):295-304. https://doi.org/10.1023/A:1012090810798

2. Yaylacı Ş, Roth WD, Jaffe K. Measuring racial essentialism in the genomic era: The genetic essentialism scale for race (GESR). Curr Psychol [Internet]. 2019 Jun 25 [cited 2021 Feb 2]; Available from: http://link.springer.com/10.1007/s12144-019-00311-z

3. Roberts JS, Ostergren J. Direct-to-Consumer Genetic Testing and Personal Genomics Services: A Review of Recent Empirical Studies. Curr Genet Med Rep. 2013 Sep;1(3):182-200.

4. Niemiec E, Kalokairinou L, Howard HC. Current Ethical and Legal Issues in Health-Related Direct-to-Consumer Genetic Testing. Pers Med. 2017 Sep;14(5):433-45. https://doi.org/10.2217/pme2017-0029.

5. Hall JA, Gertz R, Amato J, Pagliari C. Transparency of Genetic Testing Services for 'Health, Wellness and Lifestyle': Analysis of Online Prepurchase Information for UK Consumers. Eur J Hum Genet. 2017 Aug;25(8):908-17. https://doi.org/10.1038/ejhg.2017.75.

6. Hudson K, Javitt G, Burke W, Byers P. ASHG Statement on Direct-to-Consumer Genetic Testing in the United States. Am J Hum Genet. 2007 Sep;81(3):635-7.

7. Myers MF. Health Care Providers and Direct-to-Consumer Access and Advertising of Genetic Testing in the United States. Genome Med. 2011 Dec;3(12):81. https://doi.org/ 10.1186/gm297.

8. Stewart KFJ, Wesselius A, Schreurs MAC, Schols AMWJ, Zeegers MP. Behavioural Changes, Sharing Behaviour and Psychological Responses after Receiving Direct-to-Consumer Genetic Test Results: A Systematic Review and Meta-Analysis. J Community Genet. 2018 Jan;9(1):1-18. https://doi.org/10.1007/s12687-017-0310$z$.

9. Francke U, Dijamco C, Kiefer AK, Eriksson N, Moiseff B, Tung $J Y$, et al. Dealing with the Unexpected: Consumer Responses to Direct-Access BRCA Mutation Testing. PeerJ. 2013 Feb;1. https://doi.org/10.7717/peerj.8.

10. Walker $M$, Jacobson $M$, Sobel $M$. Management of Ovarian Cancer Risk in Women with BRCA1/2 Pathogenic Variants. CMAJ. 2019 Aug;191(32):886-93. https://doi.org/ 10.1503/cmaj.190281.
11. Nohdurft E, Long E, Spinler S. Was Angelina Jolie Right? Optimizing Cancer Prevention Strategies Among BRCA Mutation Carriers. Decis Anal. 2017 Jul;14(3):139-69. https://doi.org/10.1287/ deca.2017.0352.

12. Tennen RI, Laskey SB, Koelsch BL, Mclntyre MH, Tung JY. Identifying Ashkenazi Jewish BRCA1/2 Founder Variants in Individuals Who Do Not Self-Report Jewish Ancestry. Sci Rep. 2020 May;10(1):7669. https://doi.org/10.1038/s41598-020-63466-x.

13. Roth WD, Yaylacı Ş, Jaffe K, Richardson L. Do Genetic Ancestry Tests Increase Racial Essentialism? Findings from a Randomized Controlled Trial. Withers $\mathrm{MH}$, editor. PLOS ONE. 2020 Jan;15(1):0227399. https://doi.org/10.1371/ journal.pone.0227399.

14. Loike JD. Opinion: Consumer DNA Testing Is Crossing into Unethical Territories. The Scientist Magazine $®$ [Internet]. [cited 2020 Nov 19]; Available from: https://www.the-scientist.com/newsopinion/opinion-consumer-dna-testing-is-crossing-into-unethicalterritories-64650.

15. Hayden EC. The Rise and Fall and Rise Again of 23andMe. Nat News. 2017 Oct;550(7675):174. https://doi.org/10.1038/ 550174a.

16. Can Genetic Testing Influence Your Critical IIIness Insurance Rates? [Internet]. Karma Insurance. 2018. Available from: https://www.karmainsurance.ca/blog/can-genetic-testinginfluence-your-critical-illness-insurance-rates/.

17. Brandie W. Door Will Open to Genetic Discrimination If Act Protecting Canadians Is Overturned, Genomics Expert Says I CBC News. CBC [Internet]. [cited $2020 \mathrm{Nov}$ 21]; Available from: https://www.cbc.ca/news/health/genetic-nondiscrimination-act-challenge-quebec-1.4658432.

18. Weeks C. Canadian Insurance Industry Pens Rules on Use of Genetic Test Results. The Globe and Mail [Internet]. [cited 2020 Nov 21]; Available from: https://www.theglobeandmail.com/life/ health-and-fitness/health/canadian-insurance-industry-pensrules-on-use-of-genetic- test- results/ article33573054/.

19. 23andMe. How It Works [Internet]. 23andMe Canada. [cited 2020 Nov 21]. Available from: https://www.23andme.com/enca/howitworks/.

20. 23andMe. DNA Genetic Testing Analysis [Internet]. 23andMe Canada. [cited 2020 Nov 21]. Available from: https://www.23andme.com/en-ca/about/tos/.

21. 23andMe. What Unexpected Things Might I Learn from 23andMe?" 23andMe Customer Care | Canada [Internet]. 23andMe Canada. [cited 2020 Nov 21]. Available from: https://ca.customercare.23andme.com/hc/en-us/articles/ 115000915968-What-Unexpected-Things-Might-I-Learn-from23andMe-

22. 23andMe. Navigating Your Raw Data." 23andMe Customer Care [Internet]. 23andMe Canada. [cited 2020 Nov 26]. Available from: https://customercare.23andme.com/hc/en-us/articles/ 115004310067-Navigating-Your-Raw-Data. 
23. 23andMe. Ancestry Composition [Internet]. 23andMe Canada. [cited 2020 Nov 21]. Available from: https:// www.23andme.com/en-ca/ancestry-composition-guide/.

24. 23andMe. The Science Behind 23andMe Canada [Internet]. [cited 2021 May 29]. Available from: https:// www.23andme.com/en-ca/genetic-science/

25. Shakespeare T. Still a Health Issue. Disabil Health J. 2012 Jul;5(3):129-31. https://doi.org/10.1016/j.dhjo.2012.04.002.

26. Cho S, Crenshaw KW, McCall L. Toward a Field of Intersectionality Studies: Theory, Applications, and Praxis. Signs J Women Cult Soc. 2013 Jun;38(4):785-810. https://doi.org/10.1086/669608.

27. The Future of Privacy Forum. Privacy Best Practices for Consumer Genetic Testing Services [Internet]. The Future of Privacy Forum. 2018. Available from: https://fpf.org/2018/07/31/privacybest-practices-for-consumer-genetic-testing-services/.

28. Ruhl GL, Hazel JW, Clayton EW, Malin BA. Public Attitudes Toward Direct to Consumer Genetic Testing. In: AMIA . Annual Symposium Proceedings AMIA Symposium. 2019. p. 774-83.

29. Niemiec E, Borry P, Pinxten W, Howard HC. Content Analysis of Informed Consent for Whole Genome Sequencing Offered by Direct-to-Consumer Genetic Testing Companies. Hum Mutat. 2016;37(12):1248-56. https://doi.org/10.1002/humu.23122.

30. Reuter JA, Spacek DV, Snyder MP. High-Throughput Sequencing Technologies. Mol Cell. 2015 May;58(4):586-97. https://doi.org/10.1016/j.molcel.2015.05.004.

31. Arribas-Ayllon M. After Geneticization. Soc Sci Med. 2016 Jun;159:132-9. https://doi.org/10.1016/j.socscimed.2016.05. 011.

32. The FDA Warns Against the Use of Many Genetic Tests with Unapproved Claims to Predict Patient Response to Specific Medications: FDA Safety Communication [Internet]. FDA. 2020. Available from: https://www.fda.gov/medical-devices/safetycommunications/fda-warns-against-use-many-genetic-testsunapproved-claims-predict-patient-response-specific.

33. Blell M, Hunter MA. Direct-to-Consumer Genetic Testing's Red Herring: 'Genetic Ancestry' and Personalized Medicine. Front Med. 2019 Mar;6:48. https://doi.org/10.3389/fmed.2019.00048.

34. FDA Allows Marketing of First Direct-to-Consumer Tests That Provide Genetic Risk Information for Certain Conditions [Internet]. FDA. 2020. Available from: https://www.fda.gov/newsevents/press-announcements/fda-allows-marketing-firstdirect-consumer-tests-provide-genetic-risk-information-certainconditions.

35. Lippman A. Prenatal Genetic Testing and Screening: Constructing Needs and Reinforcing Inequities. Am J Law Med. 1991;17(1-2):15-50.

36. Direct to Consumer Genetic Testing (DTC Testing [Internet]. Genome BC. [cited 2020 Nov 21]. Available from: https://www.genomebc.ca/infobulletins/direct-to-consumergenetic-testing-dtc-testing/.

37. UPDATE: Understanding Genetic Testing and Life Insurance
[Internet]. LSM Insurance. 2017. Available from: https:// Isminsurance.ca/life-insurance-canada/2017/01/understandingtesting- insurance.

38. Nelson HD, Fu R, Goddard K, Mitchell JP, Okinaka-Hu L, Pappas M, et al. Risk Assessment, Genetic Counseling, and Genetic Testing for BRCA-Related Cancer: Systematic Review to Update the U.S. Preventive Services Task Force Recommendation [Internet]. Agency for Healthcare Research and Quality (US; 2013. Available from: http://www.ncbi.nlm.nih.gov/books/NBK179201/.

39. Lippi G, Mattiuzzi C, Montagnana M. BRCA Population Screening for Predicting Breast Cancer: For or Against? Ann Transl Med. 2017 Jul;5(13). https://doi.org/10.21037/atm.2017.06.71.

40. Wolf BR, Buckwalter JA. Randomized Surgical Trials and 'Sham' Surgery: Relevance to Modern Orthopaedics and Minimally Invasive Surgery. lowa Orthop J. 2006;26:107-11.

41. Schaper M, Schicktanz S. Medicine, Market and Communication: Ethical Considerations in Regard to Persuasive Communication in Direct-to-Consumer Genetic Testing Services. BMC Med Ethics. 2018 Jun;19. https://doi.org/10.1186/s12910-018-02923.

42. Scully JL. Epistemic Exclusion, Injustice, and Disability. In: Scully JL, Cureton A, Wasserman DT, editors. The Oxford Handbook of Philosophy and Disability. Oxford University Press; 2020. p. 295-309. https://doi.org/10.1093/oxfordhb/ 9780190622879.013 .8

43. Barnartt SN, Altman BM, editors. Exploring Theories and Expanding Methodologies: Where We Are and Where We Need to Go. 1st ed. JAI; 2001.

44. Norrgard K. DTC Genetic Testing for Diabetes, Breast Cancer, Heart Disease and Paternity. Nat Educ. 2008;1(1):86.

45. Blakemore E. Race and Ethnicity: How Are They Different? Culture. National Geographic [Internet]. 2019 Feb 22; Available from: https://www.nationalgeographic.com/culture/topics/reference/raceethnicity/.

46. Phelan JC, Link BG, Feldman NM. The Genomic Revolution and Beliefs about Essential Racial Differences: A Backdoor to Eugenics? Am Sociol Rev. 2013;78(2):167-91. https://doi.org/10.1177/0003122413476034.

47. Mackenzie C, Stoljar N, editors. Relational Autonomy: Feminist Perspectives on Automony, Agency, and the Social Self. Oxford University Press; 2000.

48. Brody H, Hunt LM. BiDil: Assessing a Race-Based Pharmaceutical. Ann Fam Med. 2006 Nov;4(6):556-60. https://doi.org/10.1370/afm.582.

49. Coram S, Hallinan C. Resisting Critical Analyses: Gatekeeping Issues with Australian Indigenous 'Subjects.' In: Hallinan C, Judd B, editors. Research in the Sociology of Sport [Internet]. Emerald Group Publishing Limited; 2013 [cited 2021 Feb 2]. p. 107-26. Available from: https://www.emerald.com/insight/content/doi/10.1108/S14762854(2013)0000007010/full/html 
50. Budimir D, Polasek O, Marusić A, Kolcić I, Zemunik T, Boraska V, et al. Ethical Aspects of Human Biobanks: A Systematic Review. Croat Med J. 2011 Jun;52(3):262-79. https://doi.org/10.3325/cmj.2011.52.262.

51. Harris A, Kelly SE, Wyatt S. Counseling Customers: Emerging Roles for Genetic Counselors in the Direct-to-Consumer Genetic Testing Market. J Genet Couns. 2013;22(2):277-88. https://doi.org/10.1007/s10897-012-9548-0.

52. DeAngelis JT, Farrington WJ, Tollefsbol TO. An Overview of Epigenetic Assays. Mol Biotechnol. 2008 Feb;38(2):179-83. https://doi.org/10.1007/s12033-007-9010-y.

53. Eissenberg JC. Direct-to-Consumer Genomics: Harmful or Empowering? Mo Med. 2017;114(1):26-32. 